\title{
Questes
}

\section{Les bruits de la ville : introduction}

\section{Andrea Martignoni}

\section{(2) OpenEdition}

\section{Journals}

Édition électronique

URL : http://journals.openedition.org/questes/2299

ISSN : 2109-9472

Éditeur

Les Amis de Questes

Édition imprimée

Date de publication : 15 mars 2003

Pagination : 2-3

ISSN : 2102-7188

\section{Référence électronique}

Andrea Martignoni, «Les bruits de la ville : introduction », Questes [En ligne], 3 | 2003, mis en ligne le 01 janvier 2014, consulté le 22 septembre 2020. URL : http://journals.openedition.org/questes/2299 
Un bruit s'écrie. Il résonne, là où les pierres parlent et les hommes vivent, respirent et meurent. Un bruit s'écrit, sonore, au cœur de la ville. Il trace dans l'invisible retentissement de son rythme, les traits de ce paysage sonore qui donne corps au réel. Un bruit s'écrie alors que bien d'autres font naufrage dans cette mémoire de l'impossible, mémoire qui hante toute quête dans un passé qui semble à première vue vouloir se taire. Chimères, ces absences-présences qui habitent la reconstruction de l'histoire ou sirènes d'illusions jouissantes ? Et si ces empreintes sonores que nous appelons bruits se seraient vidées dans le passage du temps de leur contenu, demeurant ainsi simple contenant, réceptacle de cris muets?

«Si l'homme ne retient pas les sons dans sa mémoire - rappelle Isidore de Séville - ils périssent, car ils ne peuvent être écrits » (De musica, Etymologies, III, 15, § 2). Jean-Marie Fritz s'appuie sur cette mort jadis annoncée et replonge ainsi avec force au cœur du débat historiographique en soulignant que «le son est par nature fragile, périssable. Inscriptible, seule la mémoire peut le préserver dans sa richesse et dans sa densité ». A l'écriture sont donc consignés des mots et des paroles, sans parler des gestes. Mais la voix, le bruit, l'éphémère variation de l'air qui met en brèche comme un éclair l'élégante monotonie des discours y apportant ce hiatus générateur d'un ébruitement, trouvent-ils demeure dans l'écriture, cet incroyable passeur du temps ? Il semblerait que non. Triste constat. Pourtant, dans l'apparent silence des vieilles cartes, enfouis sous la couche d'une fine poussière, il y a des sons qui frissonnent de reconquête. Si la rencontre avec les bruits de et dans la ville s'avère dès lors périlleuse, frôlant par là l'ineffable, cela tient à une définition qui pose problème. Qu'entendons-nous par bruit, notamment dans un contexte urbain ? Et si on fuit de ce contexte, que 
se passe-t-il ? Le bruit serait-il une de ces présences intrinsèques et structurantes de la ville définie comme «état d'âme », selon l'expression de Roberto Sabatino Lopez, reprise par l'historien italien Renato Bordone? Une ville sans bruits n'est-elle pas sa propre négation? Qu'est-ce qu'un marché sans cris? Le bruit serait-il rupture, espace de fibrillation entre langage et anti-langage aux risques de réveiller le fantôme d'une facilité manichéenne et dichotomique qui ferait du son, volontaire ou involontaire, le contraire de la musique, et d'une voix celui des paroles?

$\mathrm{Au}$ fond, la question qui nous anime tous est celle de savoir à quel moment le bruit, quel qu'il soit, devient véritable langage. Et qui parle de langage, ici de langage sonore, sous-tend nécessairement la présence d'un message, de sa codification et d'une volonté de monopoliser ce même langage. Voilà une enquête ; voilà des questions, des pistes de recherches, et qui sait, peut-être aussi un peu d'utopies. Mais nos cœurs et nos esprits se prédisposent à l'écoute. Une écoute qui se fonde, hiératique, dans le respect des absences et des présences de l'histoire du ou des possibles bruits. 